Please do not remove this page

RMIT

UNIVERSITY

\title{
ZnO nanostructured arrays grown from aqueous solutions on different substrates
}

Breedon, Michael; Yu, Jerry; Wlodarski, Wojciech; Kalantar Zadeh, Kourosh

https://researchrepository.rmit.edu.au/esploro/outputs/9921863901201341/filesAndLinks?institution=61RMIT_INST\&\&index=null

Breedon, M., Yu, J., Wlodarski, W., \& Kalantar Zadeh, K. (2008). ZnO nanostructured arrays grown from aqueous solutions on different substrates. Proceedings of the 2008 International Conference on Nanoscience and Nanotechnology, 9-12. https://doi.org/10.1109/ICONN.2008.4639232

Published Version: https://doi.org/10.1109/ICONN.2008.4639232

Repository homepage: https://researchrepository.rmit.edu.au

(c) 2008 IEEE. Personal use of this material is permitted. However, permission to reprint/republish this material for advertising or promotional purposes or for creating new collective works for resale or redistribution to servers or lists, or to reuse any copyrighted component of this work in other works must be obtained from the IEEE.

Downloaded On 2023/04/27 01:04:59 +1000 


\title{
$\mathrm{ZnO}$ Nanostructured Arrays Grown from Aqueous Solutions on Different Substrates
}

\author{
$\underline{\text { Michael Breedon }}^{1}$, Jerry $\mathrm{Yu}^{1}$, Wojtek Wlodarski ${ }^{1}$, Kourosh Kalantar-zadeh ${ }^{1}$ \\ ${ }^{1}$ Sensor Technology Laboratory, School of Electrical and Computer Engineering, RMIT University, \\ Melbourne, AUSTRALIA \\ Email: Michael.Breedon@student.rmit.edu.au
}

\begin{abstract}
ZnO nanostructures were grown from a solution of zinc nitrate hexahydrate and hexamethylenetetramine onto different substrates that were pretreated with an RF sputter coated $\mathrm{ZnO}$ seed layer. The choice of substrate was observed to have a direct effect on the morphology, orientation and surface coverage of the nanostructured arrays. Substrates that were covered in a $1.2 \mu \mathrm{m}$ sputter coated $\mathrm{ZnO}$ seed layer, include; $6 \mathrm{H}$ $\mathrm{SiC}, \mathrm{LiNbO}_{3}$, gold, $\mathrm{LiTaO}_{3}$, ITO (indium tin oxide) glass and plate glass. The $\mathrm{ZnO}$ seed layer facilitates the uniform growth of nanostructured arrays of $\mathrm{ZnO}$, without such a layer nanostructure growth was found to be sporadic and unaligned. Under identical reaction conditions, a range of different $\mathrm{ZnO}$ nanostructured arrays were observed.
\end{abstract}

Keywords-component: ZnO; Nanostructure; Array; Nanorod; Aqueous growth; Synthesis; Metal oxide.

\section{INTRODUCTION}

Research into zinc oxide nanostructures and nanostructured arrays has emerged as popular research choice due to the myriad of morphological forms and diverse range of applications. Applications, include but not limited to; gas sensor technologies [1], solar cell development [2], photonic devices and coatings [3], nanostructured templates and employed as transparent conducting oxides [4].

The aqueous growth of $\mathrm{ZnO}$ nanostructures from the hydrothermal decomposition of an equimolar $\mathrm{Zn}^{2+} /$ hexamethylenetetramine (HMT) solution provides the means for the controlled growth of nanostructured arrays of $\mathrm{ZnO}$. This method is simple, low cost, environmentally friendly, and can be easily scaled to suit larger substrate sizes.

$6 \mathrm{H}-\mathrm{SiC} \& \mathrm{LiNbO}_{3}$ and quartz substrates were purchased as semiconductor grade polished wafers, $\mathrm{Au} / \mathrm{LiTaO}_{3}$ samples were grown on inter-digitated surface, ITO glass was purchased from Sigma Aldrich $(10 \Omega \mathrm{cm}) \&$ the plate glass utilized was of a similar grade to a microscope slide.

Prior to $\mathrm{ZnO}$ nanorod growth, substrates were RF sputter coated with a $1.2 \mu \mathrm{m} \mathrm{ZnO}$ seed layer as seen in Figure 1. Such a seed layer, improves the uniformity and orientation of HMT grown $\mathrm{ZnO}$ nanostructured arrays.

Nanostructured arrays of $\mathrm{ZnO}$ were grown in a sealed reaction vessel via the hydrothermal decomposition of HMT and zinc nitrate hexahydrate $\left(\mathrm{Zn}\left(\mathrm{NO}_{3}\right)_{2} \cdot 6 \mathrm{H}_{2} \mathrm{O}\right)$ solutions in a modified process first described by L. Vayssieres [5] where $\mathrm{Zn}^{2+}$ ions originate from $\left(\mathrm{Zn}\left(\mathrm{NO}_{3}\right)_{2} \cdot 6 \mathrm{H}_{2} \mathrm{O}\right)$ and $\mathrm{OH}^{-}$ions are derived from HMT $\left(\mathrm{C}_{6} \mathrm{H}_{12} \mathrm{~N}_{4}\right)$ as written in the equation (1):

$$
\begin{aligned}
& \mathrm{C}_{6} \mathrm{H}_{12} \mathrm{~N}_{4}+6 \mathrm{H}_{2} \mathrm{O} \stackrel{\text { heat }}{\longrightarrow} 6 \mathrm{HCHO}+4 \mathrm{NH}_{3} \\
& \mathrm{NH}_{3}+\mathrm{H}_{2} \mathrm{O} \longrightarrow \mathrm{NH}_{4}^{+}+\mathrm{OH}^{-}
\end{aligned}
$$

deposition of $\mathrm{ZnO}$ occurs according to the following equation:

$$
\begin{aligned}
& \mathrm{Zn}^{2+}+2 \mathrm{OH}^{-} \longrightarrow \mathrm{Zn}(\mathrm{OH})_{2} \\
& \mathrm{Zn}(\mathrm{OH})_{2} \stackrel{\text { heat }}{\longrightarrow} \mathrm{ZnO}+\mathrm{H}_{2} \mathrm{O}
\end{aligned}
$$
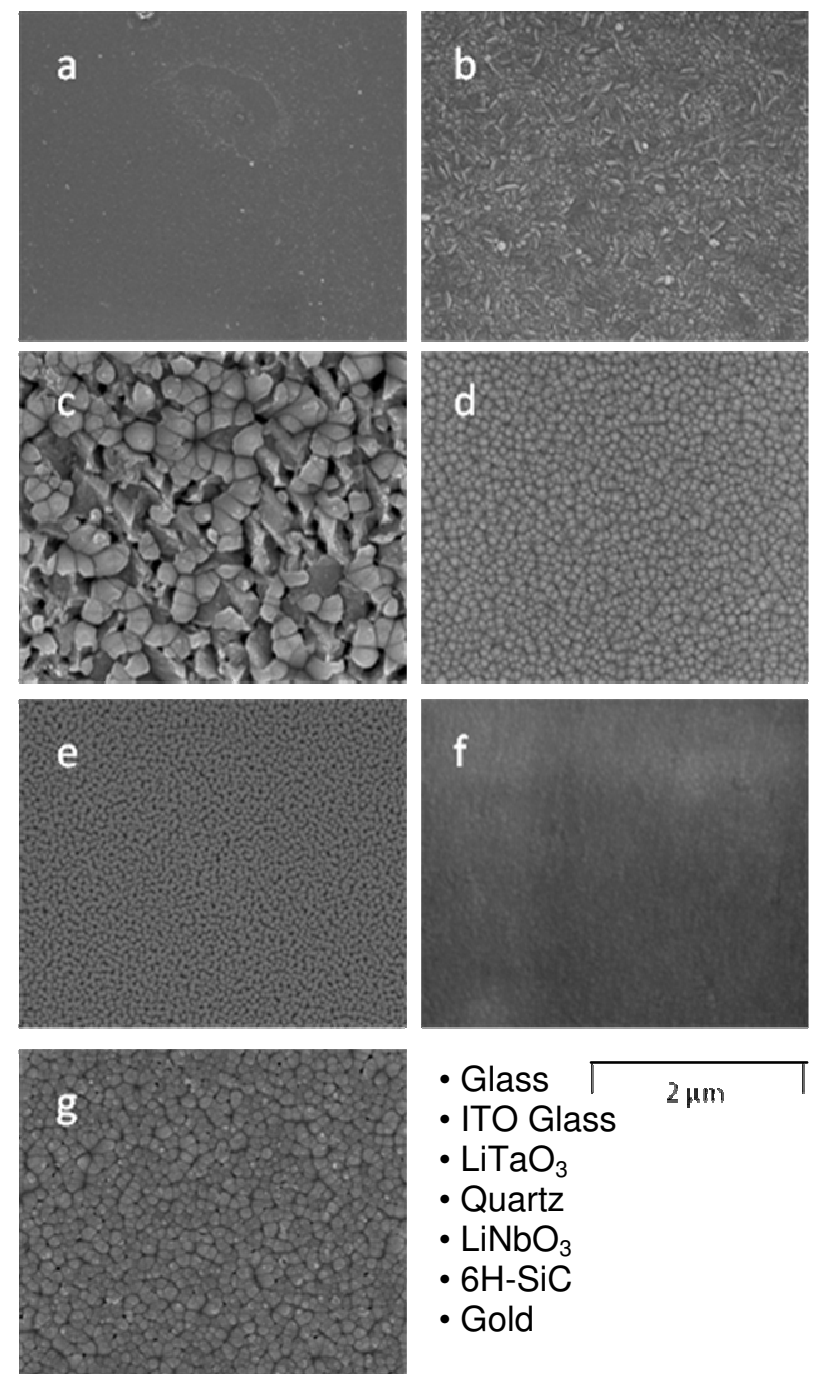

- Glass
- ITO Glass
- LiTaO
- Quartz
- LiNbO
- $6 \mathrm{H}-\mathrm{SiC}$
- Gold

Figure 1. RF sputtered $\mathrm{ZnO}$ seed layers 


\section{EXPERIMENTAL METHODOLOGY}

In this process, cleaned sputtered substrates were placed into a sample holder residing inside a reaction vessel filled with an equimolar solution of a $10 \mathrm{mM} \mathrm{HMT} / \mathrm{Zn}\left(\mathrm{NO}_{3}\right)_{2} \cdot 6 \mathrm{H}_{2} \mathrm{O}$. Vessels were sealed and placed inside a standard laboratory grade oven for 16 to $18 \mathrm{hrs}$ at $80^{\circ} \mathrm{C}$. After which the substrates were extricated and washed with DI water to remove any residual zinc salts and dried in a stream of $\mathrm{N}_{2}$.

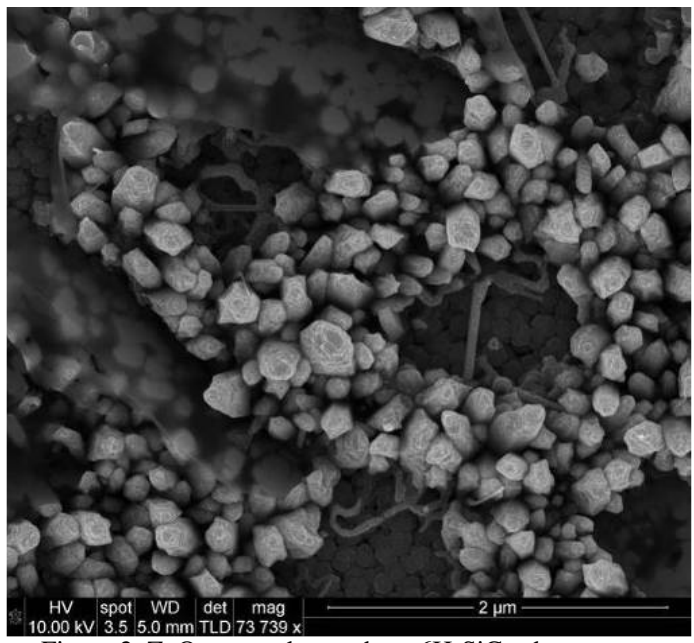

Figure 2. $\mathrm{ZnO}$ nanorod growth on $6 \mathrm{H}-\mathrm{SiC}$ substrate

Under identical preparation and reaction conditions a range of different nanostructured arrays with different surface coverages and morphologies were observed in Figs. 2-7.

\section{RESULTS}

$\mathrm{ZnO}$ growth on $6 \mathrm{H}-\mathrm{SiC}$ substrates manifests as clusters of nanorods and dispersed thin sheets of $\mathrm{ZnO}$ measuring approx $30 \mathrm{~nm}$. These nanosheets grow from the substrate and fold under their own weight, draping over the nanorods. At $10 \mathrm{kV}$ accelerating voltage during SEM imaging, there is sufficient penetration depth associated with the accelerated electrons to pass through the $30 \mathrm{~nm}$ nanosheets, interacting with the underlying nanorods. However, this decelerates the electrons as they pass through the nanosheets, such that the interaction with the underlying nanorods is weaker, thus reducing the number of detected secondary electrons, observed as obfuscated regions. Obfuscated regions are those that appear to be out of focus in Figure 2.

$\mathrm{ZnO}$ nanorods grown on $\mathrm{LiNbO}_{3}$ substrates exhibit uniform growth that occurs at relatively low densities as seen in Figure 3. $\mathrm{LiNbO}_{3}$ substrate bound nanorods have one of the largest variations in width, measuring between approx $125 \mathrm{~nm}-200 \mathrm{~nm}$.

$\mathrm{ZnO}$ nanorods grow as perpendicular arrays on all substrates, with the exception of ITO coated glass (as shown in Figure 4) displaying no preferential growth angle. Nanorods grown on ITO glass have widths of approx $120 \mathrm{~nm}$ with minimal variation between nanorods. Interestingly ITO coated glass has a comparatively rougher surface than the other substrates. It is hypothesized that this roughness may be a contributing factor in the disordered orientation of the nanorod arrays observed in Figure 4.

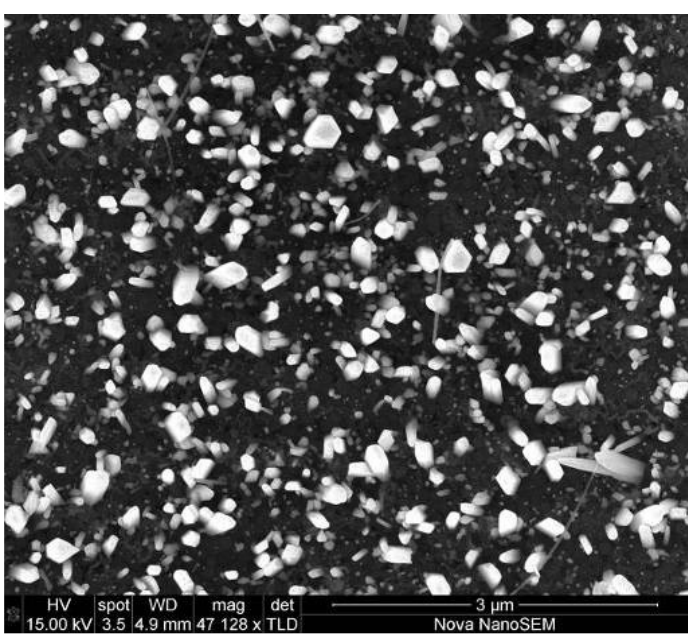

Figure 3. ZnO nanorod growth on $\mathrm{LiNbO}_{3}$ substrate

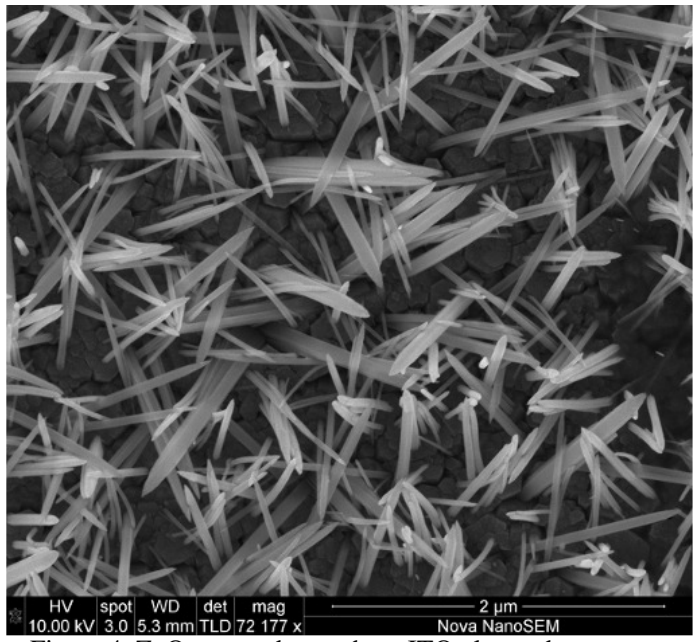

Figure 4. ZnO nanorod growth on ITO glass substrate

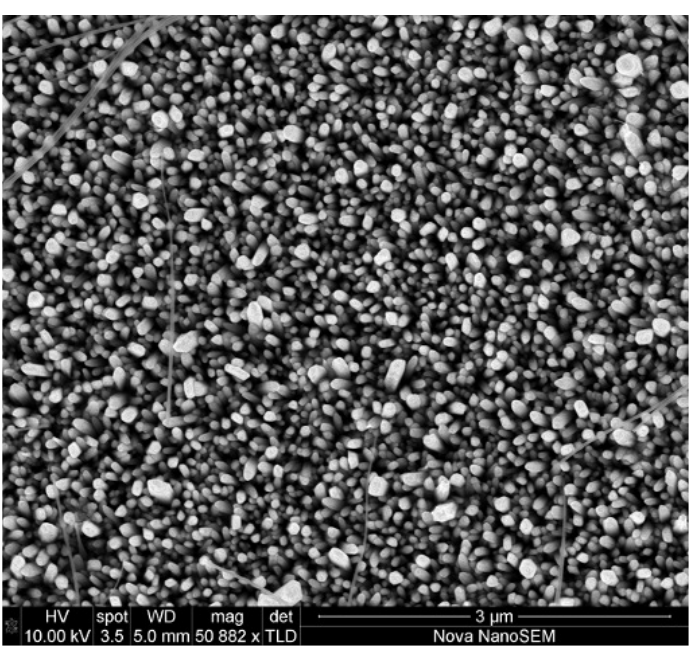

Figure $5 . \mathrm{ZnO}$ nanorod growth on glass substrate

$\mathrm{ZnO}$ nanorod growth on glass substrates shows superior proximal distribution, with excellent substrate coverage (Figure 5). These nanorods are by far the thinnest, with dimensions of approx $100 \mathrm{~nm}$ or less. Nanorod growth on quartz, as seen in Figure 6, was found to have excellent 
coverage, but suffered from minor deviations in perpendicular growth.

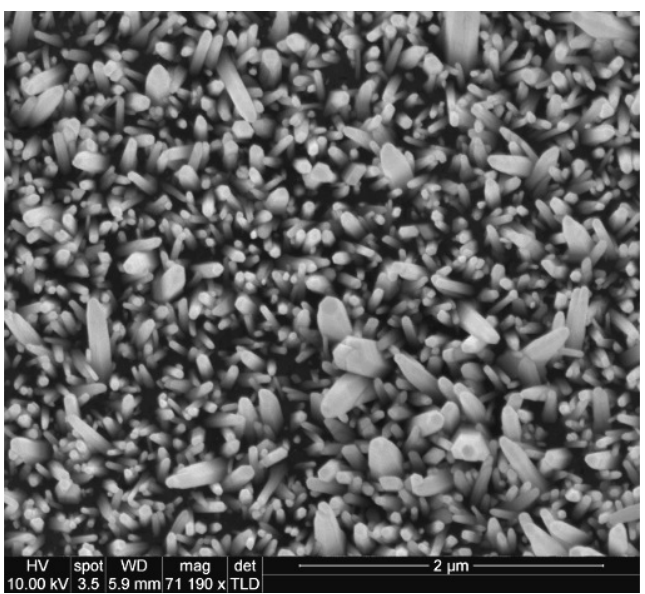

Figure $6 . \mathrm{ZnO}$ nanorods grown on quartz

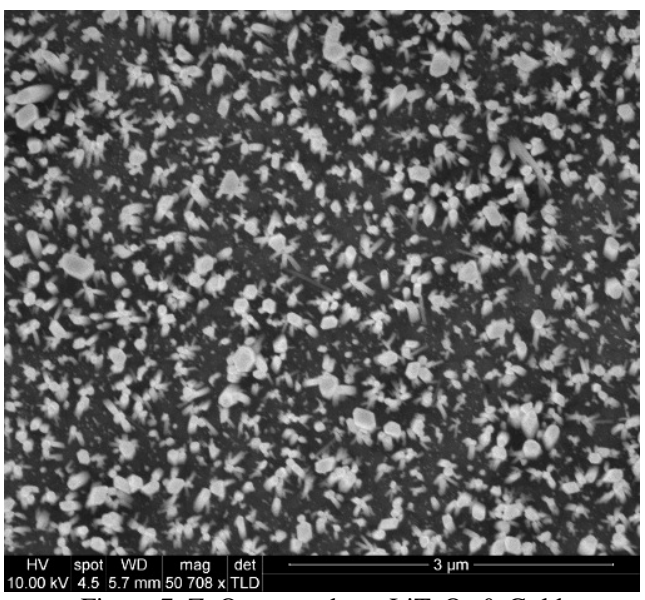

Figure 7. $\mathrm{ZnO}$ nanorods on $\mathrm{LiTaO}_{3} \&$ Gold

$\mathrm{ZnO}$ nanorods grown on $\mathrm{LiTaO}_{3}$ and gold (Figure 7) were measured to have identical densities. Despite the fact that different initial sputtered crystallite densities were recorded, this will be discussed overleaf.

\section{DENSITY APPROXIMATIONS}

Density approximations were calculated using the ImageJ software package [6]. SEM images of sputtered substrates and the subsequent nanorod growth were employed for density approximation of the sputtered crystallites and the nanorod array as seen in Table 1 . These results show that the majority of the samples show a decreasing number of surface bound structures.

Due to the high density of the sputtered crystallites, manually defining the boundaries (Figure $8 \mathrm{~b}$ ) between adjacent sputtered crystallites minimises artifacts in the image and is necessary to prevent the underestimation that occurs when two adjacent sputtered crystallites are interpreted by the software as one, this "necking" phenomenon greatly underestimates the number of sputtered crystallites. The threshold of the manually defined image was then manipulated, rendering only the outlines of the sputtered crystallites visible as seen in Figure 8c. A similar methodology was employed to analyse nanostructured arrays. This process is highlighted in Figures $8 \mathrm{a}, 8 \mathrm{~b}$ and $8 \mathrm{c}$.

TABLE I. ZNO FILM AND NANOSTRUCTURE ARRAY COMPARISON

\begin{tabular}{|l|c|c|}
\hline \multicolumn{3}{|c|}{ Density comparison $\left(\boldsymbol{\mu m}^{2}\right)$} \\
\hline Substrate & $\begin{array}{c}\text { Sputtered } \\
\text { Film }\end{array}$ & $\begin{array}{c}\text { Nanorod } \\
\text { Array }\end{array}$ \\
\hline Lithium Niobate $\left(\mathrm{LiNbO}_{3}\right)$ & 140 & 96 \\
\hline Lithium Tantalate $\left(\mathrm{LiTaO}_{3}\right)$ & 29 & 146 \\
\hline Gold $(\mathrm{Au})$ & 64 & 146 \\
\hline Glass $\left(\mathrm{SiO}_{2}\right)$ & $*$ & 202 \\
\hline ITO Glass $\left(\mathrm{In}_{2} \mathrm{SnO}_{5}\right.$ on $\left.\mathrm{SiO}_{2}\right)$ & 415 & 123 \\
\hline Quartz $\left(\mathrm{SiO}_{2}\right)$ & 244 & 188 \\
\hline Silicon $\mathrm{Carbide}_{(6 \mathrm{H}-\mathrm{SiC})}$ & 1081 & 71 \\
\hline
\end{tabular}

Densities approximated from SEM images using ImageJ software * Sputtered crystallites not observed on glass substrate

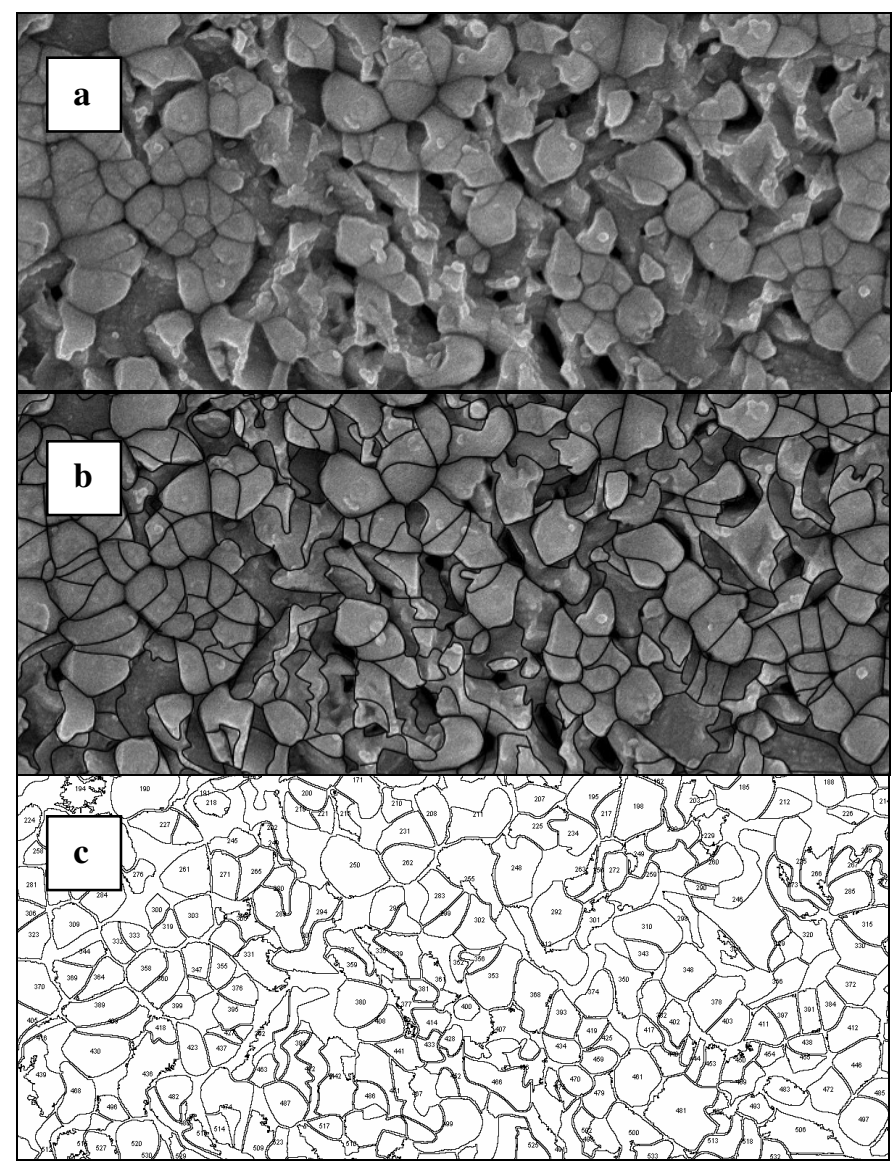

Figure 8 a) SEM image of $\mathrm{ZnO}$ sputter coated on $\mathrm{LiTaO}_{3}$ substrate, b) boundaries between adjacent crystalites are manually defined, c) outline map generated from the threshold manipulated image

\section{DISCUSSION}

As the concentration of free $\mathrm{Zn}^{2+}$ ions diminishes, the growth of the nanorods is quenched as governed by Equation (2). Initially the high concentration of $\mathrm{Zn}^{2+}$ ions shifts the equilibrium to the right facilitating the growth of $\mathrm{ZnO}$ nanorods, however as the concentration of $\mathrm{Zn}^{2+}$ ions falls, the 
system approaches equilibrium and growth of the nanorods halts. It has been noted in literatures, that in harsher $\mathrm{NaOH}$ growth solutions the thermodynamically unfavourable tip of the rod was rendered into a flat top, effectively signalling the point at which the reaction had successfully reached equilibrium [6]. The $\mathrm{ZnO}$ nanorods presented in this paper taper to a fine tip, suggesting that the nanorods have not yet fully matured and could possibly grow longer. Additionally, the growth scheme has been modified by increasing the reaction length, a lower reaction temperature $\left(80^{\circ} \mathrm{C}\right.$ instead of $90^{\circ} \mathrm{C}$ ), and the suspended nature of substrate which may contribute to the tips observed. As a precaution, all reaction vessels were rinsed with weak nitric acid to remove any precipitates that had accrued between consecutive reactions (visible as a hazy film on the inside of the reaction vessel).

It has been reported in literature for reaction times of less than three hours, in high $\mathrm{pH}$ solutions that the type and density of $\mathrm{ZnO}$ seed layer has no bearing on the densities of nanorod arrays [4]. Furthermore, it has been postulated that the growth of $\mathrm{ZnO}$ nanorods from high $\mathrm{pH}$ solutions are a direct extension of crystallites that comprise the seed layer [4]. In this study, a mild $\mathrm{pH}$ growth solution and longer growth times were employed to investigate if such a hypothesis would be valid. If such a hypothesis was correct, one would expect to see a similar number of nanorods growing to the initial number of sputtered crystallites seen in Table 1.

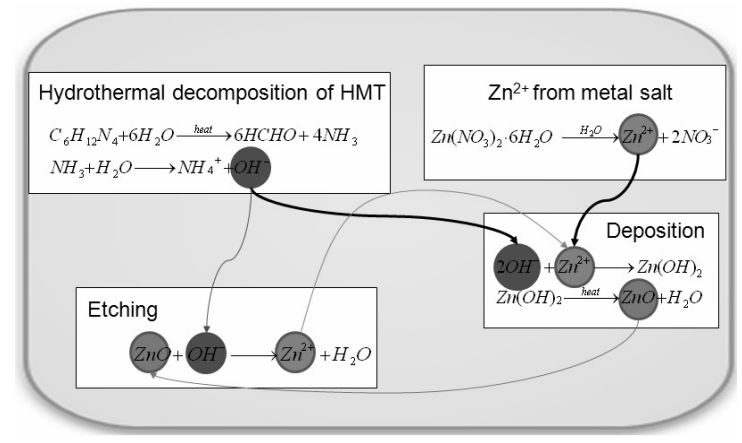

Figure 9. Ostwald ripening process (dominant pathways denoted in black)

With the exclusion of $\mathrm{Au} / \mathrm{LiTaO}_{3}$ sample, it has been shown that this hypothesis is not valid. This discrepancy is ascribed to Ostwald ripening effects, defined as "the last stage of a condensation transition from liquid to solid", where smaller particles (sputtered crystallites) can shrink to their critical nucleus size and rapidly vanish because of the thermodynamic instability of subcritical clusters [7]. Initially, the high concentration of $\left[\mathrm{Zn}(\mathrm{OH})_{2}\right]^{0}$ is responsible for the growth of perpendicular $\mathrm{ZnO}$ nanorods, however as the reaction approaches equilibrium and the concentration of $\mathrm{Zn}^{2+}$ ions drops, smaller and less stable $\mathrm{ZnO}$ crystallites are dissolved and their zinc content is utilized to fortify the larger more thermodynamically stable nanorods, pictorially illustrated in Figure 9. The small number of sputtered crystallites (i.e. large crystallite sizes such as the $\mathrm{Au} / \mathrm{LiTaO}_{3}$ sample) results in nanostructured arrays that are comprised of nanorod growth regions which are not indigenous to the underlying crystallites size (i.e. more than one nanorod is capable of growing from a single large seed crystallite). Interestingly, this appears to be linked with a stabilisation effect that occurs when a substrate is patterned with another material. This is evident in the $\mathrm{Au} / \mathrm{LiTaO}_{3}$ samples, where an interdigitated surface was RF sputter coated with a $\mathrm{ZnO}$ seed layer, with different seed layer densities for the different underlying substrates. The resultant nanorod arrays appear to have an identical density, regardless of the underlying material upon which they have grown. This may be due to light etching of the seed layer that may occur, which is tied to the release of free hydroxide ions that takes place during the hydrothermal decomposition of HMT in an aqueous environment as seen in Equation (1). This would effectively increase the concentration of free $\mathrm{Zn}^{2+}$ ions as $\mathrm{ZnO}$ is etched by the hydroxide, driving the reaction to deposit $\mathrm{ZnO}$ as seen in Equation (3). Thus, fortifying the arrays via selective redeposition as defined using Equation (2).

$$
\mathrm{ZnO}+\mathrm{OH}^{-} \longrightarrow \mathrm{Zn}^{2+}+\mathrm{H}_{2} \mathrm{O}
$$

\section{CONCLUSION}

In all observations $\mathrm{ZnO}$ nanorods grown from HMT solutions exhibit excellent dimensional control, with minimal variation between nanorods. Coverage across all substrates was excellent on a macro scale, with insignificant morphological or density discrepancy on larger scales. Density appears to be substrate dependant with $\mathrm{SiC}$ displaying the lowest density of nanorods, whereas glass substrates were found to have the highest nanorod density of any substrate tested. It has been experimentally demonstrated in this work that there are density differences between sputtered $\mathrm{ZnO}$ seed layers. It has been derived, that there is non-linear correlation between the number of sputtered crystallites and the number of nanorods grown. This non-linearity is most likely due to the effects of Ostwald ripening. However, it is clear that the growth of $\mathrm{ZnO}$ nanostructured arrays from HMT solutions on RF sputter coated $\mathrm{ZnO}$ substrates is a function of sputtered crystallite size, with most arrays obeying a decreasing trend between the number of seeds and the number of nanorods grown.

\section{REFERENCES}

[1] P. Mitra, A. P. Chatterjee, and H. S. Maiti, "ZnO thin film sensor," Materials Letters, vol. 35, pp. 33-38, 1998.

[2] L. Vayssieres, "Advanced semiconductor nanostructures," Comptes Rendus Chimie, vol. 9, pp. 691-701, 2006.

[3] M. Wang, K. E. Lee, S. H. Hahn, E. J. Kim, S. Kim, J. S. Chung, E. W. Shin, and C. Park, "Optical and photoluminescent properties of sol-gel Aldoped ZnO thin films," Materials Letters, vol. 61, pp. 1118-1121, 2007.

[4] R. B. Peterson, C. L. Fields, and B. A. Gregg, "Epitaxial chemical deposition of $\mathrm{ZnO}$ nanocolumns from $\mathrm{NaOH}$," Langmuir, vol. 20, pp. 5114$5118,2004$.

[5] L. Vayssieres, "Growth of Arrayed Nanorods and Nanowires of $\mathrm{ZnO}$ from Aqueous Solutions," Advanced Materials, vol. 15, pp. 464-466, 2003.

[6] Rasband, W.S., ImageJ, U. S. National Institutes of Health, Bethesda, Maryland, USA, http://rsb.info.nih.gov/ij/, 1997-2008.

[7] G. Madras and B. J. McCoy, "Temperature effects during Ostwald ripening," The Journal of Chemical Physics, vol. 119, pp. 1683-1693, 2003. 